\title{
What is the prevalence of current alcohol dependence and how is it measured for Indigenous people in Australia, New Zealand, Canada and the United States of America? A systematic review
}

\author{
Teagan J. Weatherall ${ }^{1 *}\left(\mathbb{0}\right.$, Katherine M. Conigrave ${ }^{1,2}$, James H. Conigrave ${ }^{1}$ and K. S. Kylie Lee ${ }^{1,3}$
}

\begin{abstract}
Background: Alcohol affects Indigenous communities globally that have been colonised. These effects are physical, psychological, financial and cultural. This systematic review aims to describe the prevalence of current (12-month) alcohol dependence in Indigenous Peoples in Australia, New Zealand, Canada and the United States of America, to identify how it is measured, and if tools have been validated in Indigenous communities. Such information can help inform estimates of likely treatment need.
\end{abstract}

Methods: A systematic search of the literature was completed in six electronic databases for reports on current alcohol dependence (moderate to severe alcohol use disorder) published between 1 January 1989-9 July 2020. The following data were extracted: (1) the Indigenous population studied; country, (2) prevalence of dependence, (3) tools used to screen, assess or diagnose current dependence, (4) tools that have been validated in Indigenous populations to screen, assess or diagnose dependence, and (5) quality of the study, assessed using the Appraisal Tool for CrossSectional Studies.

Results: A total of 11 studies met eligibility criteria. Eight were cross-sectional surveys, one cohort study, and two were validation studies. Nine studies reported on the prevalence of current (12-month) alcohol dependence, and the range varied widely (3.8-33.3\% [all participants], 3-32.8\% [males only], 1.3-7.6\% [females only]). Eight different tools were used and none were Indigenous-specific. Two tools have been validated in Indigenous (Native American) populations.

Conclusion: Few studies report on prevalence of current alcohol dependence in community or household samples of Indigenous populations in these four countries. Prevalence varies according to sampling method and site (for example, specific community versus national). Prior work has generally not used tools validated in Indigenous contexts. Collaborations with local Indigenous people may help in the development of culturally appropriate ways of measuring alcohol dependence, incorporating local customs and values. Tools used need to be validated in

\footnotetext{
*Correspondence: teagan.weatherall@sydney.edu.au

1 Faculty of Medicine and Health, Discipline of Addiction Medicine, NHMRC Centre of Research Excellence in Indigenous Health and Alcohol, The University of Sydney, King George V Building, 83-117 Missenden Road, Camperdown, NSW 2050, Australia

Full list of author information is available at the end of the article
}

(c) The Author(s) 2020. This article is licensed under a Creative Commons Attribution 4.0 International License, which permits use, sharing, adaptation, distribution and reproduction in any medium or format, as long as you give appropriate credit to the original author(s) and the source, provide a link to the Creative Commons licence, and indicate if changes were made. The images or other third party material in this article are included in the article's Creative Commons licence, unless indicated otherwise in a credit line to the material. If material is not included in the article's Creative Commons licence and your intended use is not permitted by statutory regulation or exceeds the permitted use, you will need to obtain permission directly from the copyright holder. To view a copy of this licence, visit http://creativeco mmons.org/licenses/by/4.0/. The Creative Commons Public Domain Dedication waiver (http://creativecommons.org/publicdomain/ zero/1.0/) applies to the data made available in this article, unless otherwise stated in a credit line to the data. 
Indigenous communities, or Indigenous-specific tools developed, validated and used. Prevalence findings can inform health promotion and treatment needs, including funding for primary health care and specialist treatment services.

Keywords: Indigenous, Australia, New Zealand, Canada, United States of America, Alcohol, Dependence, Prevalence, Screening, Assessment

\section{Background}

Alcohol affects Indigenous communities globally that have been colonised. These effects are physical, psychological, financial and cultural in nature $[1,2]$. Colonisation, economic marginalisation, and governments' systematic efforts to erode 'Country' (land, homelands) and culture causes trauma that continues to affect Indigenous Peoples. As a result, Indigenous Peoples are at increased risk of alcohol use disorders (AUDs), including alcohol dependence (moderate to severe AUD). Alcohol dependence can then erode the strengths of Indigenous Peoples-strong families, strong communities, strong culture, and traditional responsibilities. Concerns have been expressed about Indigenous Peoples' lack of access to appropriate treatment for alcohol dependence [3, 4]. One step towards assessing likely treatment need is to have sound estimates of the prevalence of current alcohol dependence.

The World Health Organization's (WHO) International Classification of Diseases (11th revision; ICD-11) and the American Psychiatric Association Diagnostic and Statistical Manual of Mental Disorders (5th revision; DSM-5) set out guidelines for identifying alcohol dependence or moderate to severe AUDs $[5,6]$. In this paper we use the ICD-11 term 'current alcohol dependence. The World Health Organization describes dependence on alcohol as a strong internal drive to use alcohol that leads to inability to control use of alcohol, priority given to alcohol over other activities, and physiological features (e.g. 'shakes' when stopping use or first thing in the morning when waking up) [5]. However, it is not clear how well diagnostic guidelines for dependence apply to Indigenous Peoples [7].

Individuals who are dependent on alcohol typically experience greater harms than those with less severe AUDs, and require more intensive treatment $[8,9]$. Globally, there is a need for reliable population data that can inform the planning of programs to prevent, identify and treat alcohol dependence [7, 10, 11]. Prevalence of current alcohol dependence (12-month) for the general population has been reported. For example, in Australia it is 1.4\% [12], in New Zealand 1.3\% (both using DSM-IV) [13], in Canada 4.1\% (ICD-10) [14], and the United States of America (USA) 3.8\% (DSM-IV) [15]. However, few studies assess the prevalence of current alcohol dependence in Indigenous communities in colonised countries (e.g. Australia, New Zealand, Canada and USA).

A range of tools have been used to screen for, assess or diagnose alcohol dependence. Screening tools include the Alcohol Use Disorders Identification Test (AUDIT) [16], CAGE [17], and the Michigan Alcoholism Screening Test (MAST) [18]. Diagnostic tools include the WHOComposite International Diagnostic Interview (CIDI) [19], and The Schedule for Affective Disorders and Schizophrenia (SADS) [20]. Screening tools, if accurate, are useful to give an estimate of likely prevalence of alcohol dependence and so an estimate of likely treatment needs. Diagnostic tools, again if accurate, provide actual prevalence of current alcohol dependence and so a more precise estimate of likely treatment needs. However, the majority of tools have not been validated for Indigenous Peoples, and it is unclear how suitable they are for this context. For example, tools based on the DSM-V assess whether recurrent alcohol use affects obligations at work, school, or home [6]. This could mean attending school every day, pursuing further training or university, and going to work. But, in a remote Indigenous community in Australia, for example, there may not be a secondary school, nor university, and there may be limited employment opportunities [21]. Also, for some Indigenous people priority is given to community, culture and Country over 'the home'.

To address these gaps in the literature, this systematic review aims to: 1) describe the prevalence of current (12-month) alcohol dependence in community or household samples in Indigenous Peoples in Australia, New Zealand, Canada and the USA; 2) identify which tools have been used to measure alcohol dependence for these peoples; and 3) identify if those screening or assessment tools have been validated, both for general and Indigenous populations.

\section{Methods}

This systematic review has been registered with the International Prospective Register of Systematic Reviews (Prospero; ID number: CRD42019125352) [22].

A search of the literature was completed for studies published from 1 January 1989-9 July 2020. Searches were conducted of six electronic databases (Scopus, Medline, Embase, PsycInfo, CINAHL and Web of Science). 
We sought feedback on the search strategy (Table 1) from experts in drug and alcohol research, and a librarian.

As shown in the Preferred Reporting Items for Systematic Reviews and Meta-Analyses (PRISMA) diagram (Fig. 1), the search returned 2306 results, with 134 of these records identified through hand searching. Then 922 duplicates were removed. We screened titles and abstracts for the remaining 1384. Following title and abstract screen, 1225 were excluded. Of the remaining 159 studies, full-text screen was completed in duplicate by two researchers. Articles were excluded if (1) they did not report on prevalence of current alcohol dependence or on validation of tools, (2) where prevalence of dependence was assessed only in a specialised sub-population (such as patients engaged in AUD treatment or prison inmates, where dependence would be expected to be

\section{Table 1 Search strategy used for systematic review}

1 Indigenous OR Aborigin* OR "First Nation*" OR "First People*" OR "Torres Strait*" OR "Oceanic ancestry group*" OR Maori* OR "Native America*" OR "American Indian*" OR "Alaska* native*" OR"Native Canad*"OR Inuit* OR Metis*

2 Austral* OR "New Zealand*" OR Aotearoa* OR USA OR "United States*" OR Alaska* OR Canad* OR "North Americ*"

3 (substance w/3 disorder*) OR alcoholi* OR AUD OR (alcohol w/3 depend*) OR (alcohol w/3disorder*) OR (alcohol w/3 withdraw*) OR (alcohol w/3 tremor*) OR (alcohol w/3 shak*) OR (alcohol w/3 addict*)

4 Tool* OR Questionnaire* OR Survey* OR Instrument* OR Criteri* OR Valid* OR SDS OR "Severity of dependence*" OR CIDI OR "Composite International Diagnostic Interview*" OR "Indigenous Risk Impact Screen*" OR "Alcohol Use Disorders Identification Test*" OR DSM OR "Diagnostic and Statistical Manual*" OR ICD OR "International classification of disease*" OR CAGE OR MAST OR "Michigan Alcohol Screening Test*" OR DASS OR "Depression Anxiety Stress Scales*" OR "Alcohol Smoking and Substance Involvement Screening Test*" OR SADQ OR "Severity of Alcohol Dependence Questionnaire*" OR "Leeds Dependence Questionnaire *" OR ASI OR "Addiction Severity Index*"

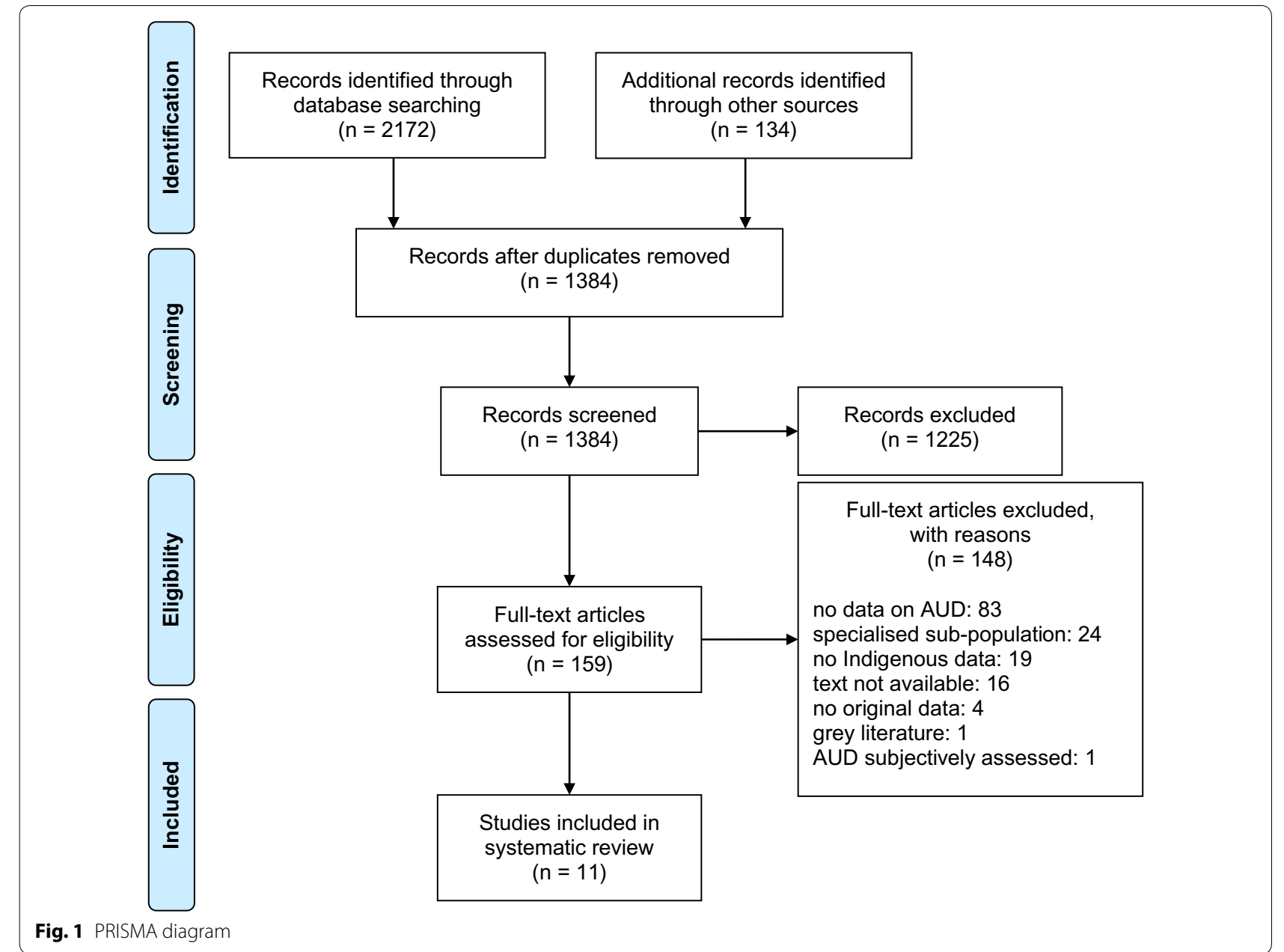


different from in the general population), (3) that did not report alcohol dependence data separately for Indigenous Peoples (from Australia, New Zealand, Canada or the United States), (4) where dependence was assessed subjectively (e.g. by clinical assessment, rather than using a tool), (5) full text not available, (6) grey literature, and (7) that did not present original data (i.e. commentary or review article). Eleven studies met criteria for inclusion in this systematic review (Fig. 1).

The following data were extracted from each included study: (1) Indigenous population(s) studied; country (or countries) of study (Australia, New Zealand, Canada, USA), (2) prevalence of current alcohol dependence in the Indigenous sample, (3) the tools used to screen, assess, or diagnose alcohol dependence, (4) the tools that have been validated in Indigenous populations to screen, assess, or diagnose alcohol dependence, and (5) the quality of the study, assessed using the Appraisal Tool for Cross-Sectional Studies (AXIS) [23]. Data were extracted in duplicate by two researchers. Differences were resolved by discussion, or where necessary by a third researcher.

\section{Results}

The 11 included studies were of populations from the USA, Canada and New Zealand (USA $=8$, USA/Canada $=2$, New Zealand $=1$ ) and were published from 1992 to 2020, inclusive (Table 2). Nine were prevalence studies, and two were validation studies. No studies were conducted in Australia.

\section{Demographics}

The majority of studies $(n=7 / 11)$ were of one or two specific communities or tribal populations [24-30]. Four studies were national representative surveys [21, 31-33], of which two used census data [21,31]. Of the seven local and regional prevalence studies, just one reported on the exact size of the total Indigenous population (426 persons) [25]. Of the two studies that used national census data, one did not report the total population size [31]; the other reported the total population of Native Americans as 5.2 million [21]. Where stated, sample sizes in prevalence studies ranged from 105 to 2595 persons [21, 24, $25,28-30,32]$, and in validation studies from 214 to 2854 $[26,27]$. Two national studies did not report on the number of Indigenous people in their sample [31, 33]. The two reports that presented validation data drew on overlapping samples from a US Southwestern tribal population $[26,27]$. Of studies confined to one or more regions, most did not describe rurality of participants. One US sample was from an urban region [24]; another US study reported that $38.2 \%$ of men and $35.9 \%$ of women were from a rural area [21].
Just under half the reports described the socioeconomic status of the sample. One US study reported that $67.8 \%$ of the sample were unemployed, $70.4 \%$ had graduated from high school and $11.4 \%$ had a university qualification [24]. In contrast, another US study reported that $43.6 \%$ of men and $50.3 \%$ of women were university educated [21]. In the latter sample, $42.4 \%$ of men and $70.1 \%$ of women had an individual income of less than $\$ 19,000$ (USD). Lastly, one US study reported $54.3 \%$ of the sample as poor [28].

\section{Study design and recruitment}

The majority of prevalence studies were cross-sectional surveys of community-based samples [24, 25, 28, 30, 32, $33]$, including the two studies that used US census data $[21,31]$. One was a cohort study [29]. Five studies used stratified recruitment [28]; three specified this process was randomised [21, 31, 33], and one systematic [32]. Four studies used a convenience sampling strategy [24, $25]$, and two specified this was based on tribal rolls, attempting to contact all eligible individuals $[29,30]$.

Both of the validation studies $[26,27]$ used a range of recruitment methods, founded on pedigree-based sampling, and respondent-driven sampling.

\section{Prevalence of current alcohol dependence}

In the nine studies that reported current (12-month) alcohol dependence for the whole sample (or this information could be calculated), the prevalence varied considerably (3.8-33.3\%) [21, 24, 25, 28-33]. Six studies reported the prevalence stratified by gender [21, 25, 28-30,33]. In all but one [30], the prevalence for males was higher than for females (range: $3.0-32.8 \%$ versus $1.3-7.6 \%$ ). The studies which reported on specific communities or regions typically had higher prevalence (3.8-33.3\%) [24, 25, 28-30], than those which had national samples (3.9-16.6\%) [21, 31-33].

\section{Detecting alcohol dependence}

All 11 studies used interviewer-administered tools to detect alcohol dependence. This included screening tools (CAGE-T, SADS-L, SMAST) and diagnostic tools (AUDADIS [Alcohol Use Disorder and Associated Disabilities Interview schedule] [34], CIDI, DIS [Diagnostic Interview Schedule] [35], UM-CIDI, WMH-CIDI) (Table 3). The CAGE-T is a variant of CAGE with an additional question ("Have you ever been treated for alcoholism?") [27]. Three studies used tools that were administered by clinicians (e.g. psychologists, psychiatrists, or social workers) [25-27]; and two used tools administered by non-clinicians [21,31]. Another four studies did not report who administered the tool(s) $[24,28,32,33]$. Two studies used tools administered by 
Table 2 General characteristics of the studies identified $(n=11)$

\begin{tabular}{|c|c|c|c|c|c|c|c|}
\hline Authors (year) & Country & $\begin{array}{l}\text { Year/s data } \\
\text { collected }\end{array}$ & $\begin{array}{l}\text { Indigenous } \\
\text { people }\end{array}$ & $\begin{array}{l}\text { Target } \\
\text { population }\end{array}$ & $\begin{array}{l}\text { Total } \\
\text { Indigenous } \\
\text { population size }\end{array}$ & $\begin{array}{l}\text { Indigenous } \\
\text { sample } \\
\text { size: } n\end{array}$ & Study design \\
\hline \multicolumn{8}{|c|}{ Prevalence studies $(n=9)$} \\
\hline $\begin{array}{l}\text { Baxter et al. } \\
\quad(2006) \text { [32] }\end{array}$ & $\mathrm{NZ}$ & $2003-2004$ & Maori & $\begin{array}{c}\text { Maori adults } \\
\text { nationally }\end{array}$ & Not reported & 2595 & $\begin{array}{l}\text { Cross-sectional } \\
\text { survey }\end{array}$ \\
\hline $\begin{array}{l}\text { Brave Heart et al. } \\
\quad(2016)[21]\end{array}$ & USA & $2001-2002$ & $\begin{array}{l}\text { Native American } \\
\text { and Alaskan } \\
\text { Natives (NA/ } \\
\text { AN) }\end{array}$ & $\begin{array}{l}\text { USA adults for } \\
\text { national census }\end{array}$ & $\begin{array}{l}5.2 \text { million (in } \\
2010 \text { ) }\end{array}$ & 701 & $\begin{array}{l}\text { Cross-sectional } \\
\text { survey (census) }\end{array}$ \\
\hline $\begin{array}{l}\text { Gill et al. (1997) } \\
\text { [24] }\end{array}$ & USA & Not reported & Native Americans & $\begin{array}{l}\text { Native Americans } \\
\text { living in Denver }\end{array}$ & Not reported & 105 & $\begin{array}{l}\text { Cross-sectional } \\
\text { survey }\end{array}$ \\
\hline $\begin{array}{l}\text { Grant et al. } \\
\quad(2017) \text { [31] }\end{array}$ & USA & $2012-2013$ & Native Americans & USA adults & Not reported & Not reported & $\begin{array}{l}\text { Cross-sectional } \\
\text { survey (census) }\end{array}$ \\
\hline $\begin{array}{l}\text { Grant et al. } \\
\text { (2004) [33] }\end{array}$ & USA & 1991-1992 & $\begin{array}{l}\text { Native American } \\
\text { and Alaskan } \\
\text { Natives (NA/ } \\
\text { AN) }\end{array}$ & $\begin{array}{l}\text { USA adults } \\
\text { nationally }\end{array}$ & Not reported & Not reported & $\begin{array}{l}\text { Cross-sectional } \\
\text { survey }\end{array}$ \\
\hline $\begin{array}{l}\text { Kinzie et al. } \\
\text { (1992) [25] }\end{array}$ & USA & $\begin{array}{l}1988 \text { (versus } \\
\text { 1969) }\end{array}$ & Native Americans & $\begin{array}{l}\text { One village in } \\
\text { western USA }\end{array}$ & 426 & 131 & $\begin{array}{l}\text { Cross-sectional } \\
\text { survey }\end{array}$ \\
\hline $\begin{array}{l}\text { Spicer et al. } \\
\text { (2003) [28] }\end{array}$ & USA & 1997-1999 & Native Americans & $\begin{array}{l}\text { Adults in } \\
\text { Southwest } \\
\text { and Northern } \\
\text { Plains tribes; } \\
\text { compared with } \\
\text { data collected } \\
\text { by the National } \\
\text { Comorbidity } \\
\text { Survey (NCS) }\end{array}$ & Not revealed ${ }^{1}$ & $\begin{array}{l}A^{2} \cdot 1446 \\
B^{3} \cdot 1638\end{array}$ & $\begin{array}{l}\text { Cross-sectional } \\
\text { survey }\end{array}$ \\
\hline $\begin{array}{l}\text { Walls et al. } \\
\text { (2020) [29] }\end{array}$ & USA and Canada & 2017-2018 & $\begin{array}{l}\text { American Indian } \\
\text { and First } \\
\text { Nations Com- } \\
\text { munities }\end{array}$ & $\begin{array}{l}\text { Young adults } \\
\text { from single } \\
\text { Indigenous } \\
\text { cultural group }\end{array}$ & Not reported & 453 & Cohort study \\
\hline $\begin{array}{c}\text { Whitbeck et al. } \\
\text { (2006) [30] }\end{array}$ & USA and Canada & $2002-2003$ & $\begin{array}{l}\text { American Indian } \\
\text { and First } \\
\text { Nations Com- } \\
\text { munities }\end{array}$ & $\begin{array}{l}\text { Parents and } \\
\text { caretakers from } \\
\text { single Indig- } \\
\text { enous cultural } \\
\text { group }\end{array}$ & Not reported & 861 & $\begin{array}{l}\text { Cross-sectional } \\
\text { survey }\end{array}$ \\
\hline \multicolumn{8}{|c|}{ Validation studies $(n=2)$} \\
\hline $\begin{array}{l}\text { Robin et al. } \\
\text { (2004) [26] }\end{array}$ & USA & 1989-1995 & Native Americans & $\begin{array}{l}\text { Southwestern } \\
\text { and Plains } \\
\text { adults (location } \\
\text { not specified) }\end{array}$ & 8578 & $\begin{array}{l}A^{4} \cdot 456 \\
B^{5} \cdot 214\end{array}$ & Validation study \\
\hline $\begin{array}{l}\text { Saremi et al. } \\
\text { (2001) [27] }\end{array}$ & USA & $\begin{array}{l}A^{6} .1991-1995 \\
B^{7} .1991-1995 \\
C^{8} .1992-1999\end{array}$ & Native Americans & $\begin{array}{l}\text { Location not } \\
\text { specified }\end{array}$ & Not revealed ${ }^{1}$ & $\begin{array}{l}A^{6} .307 \\
B^{7} .275 \\
C^{8} .2854\end{array}$ & Validation study \\
\hline
\end{tabular}

1 Withheld to protect the anonymity of the communities

2 Southwest participants (Spicer et al.)

3 Northern Plains participants (Spicer et al.)

${ }^{4}$ Southwestern participants (Robin et al.)

${ }^{5}$ Plains participants (Robin et al.)

6 Psychiatric interview only (Saremi et al.)

7 Both CAGE and psychiatric interview (Saremi et al.)

${ }^{8}$ CAGE questionnaire only (Saremi et al.)

Native community interviewers [29, 30]. One used an additional tool (SMAST) that was self-administered by some or all participants [26].
Of the eight tools used all but one have been validated for general population use [17-20, 34, 35] (Table 4). Only one tool used in the studies had not been validated (WMH-CIDI), but this tool has been shown to 


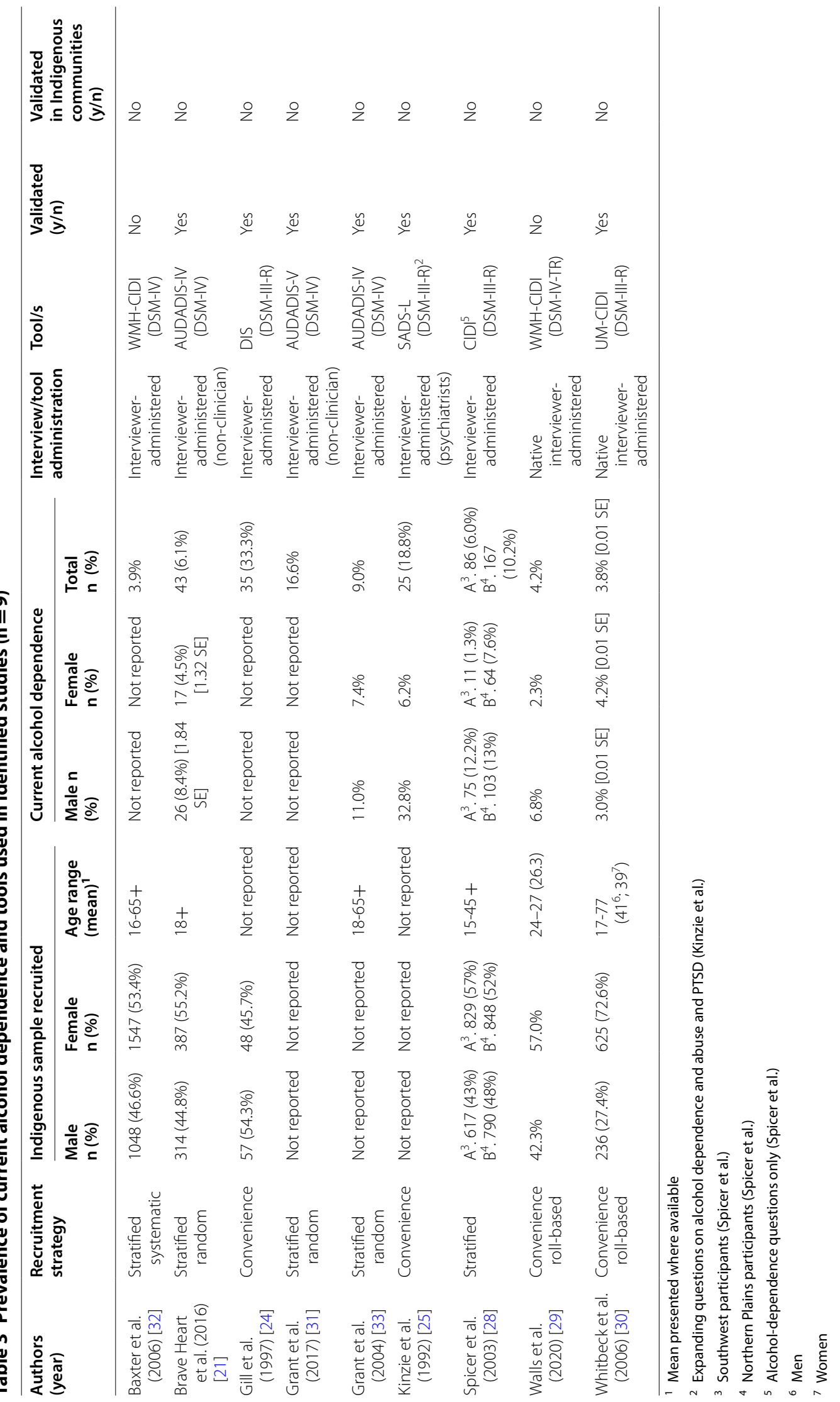




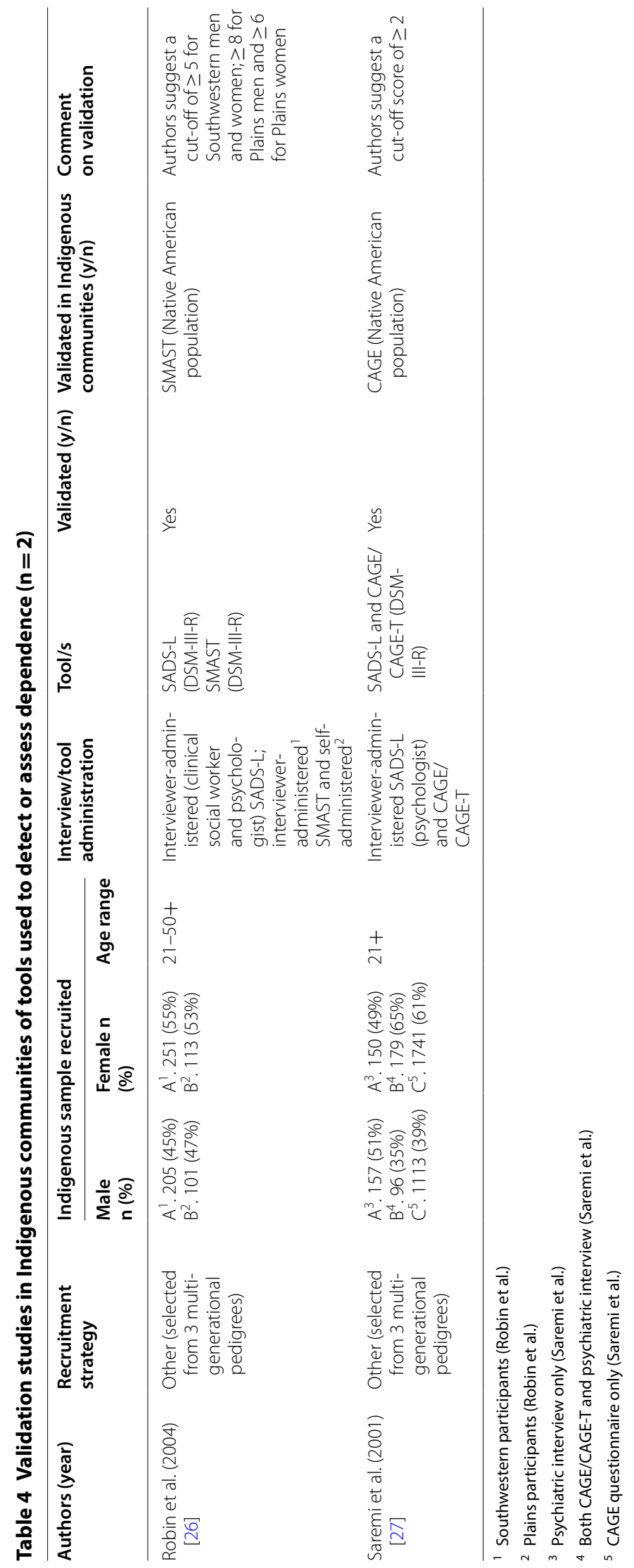


be consistent with clinical diagnoses [36]. Two screening tools, SMAST and CAGE/CAGE-T, were validated in overlapping Native American tribal samples [26, 27]. Both were compared against a lifetime diagnosis of dependence, according to SADS-L, rather than against current dependence. Area under the receiver operating characteristic (ROC) curve for the SMAST for men and women was $85-86 \%$ and $82-88 \%$, respectively [26]. However, the authors conclude that the SMAST was not a valid tool in this setting because of elevated cut-offs, and big differences in cut-offs between populations and genders. Area under the ROC curve for CAGE for men and women was $81 \%$ and $75 \%$, respectively [27] and for the modified CAGE-T was $79 \%$ and $76 \%$, respectively [27].

\section{Study quality}

Study quality was examined with the AXIS critical appraisal tool [23]. Aims and objectives were clear in ten of the 11 studies [21, 24-27, 29-33]. All studies were designed appropriately for their stated aims. The reference populations were clearly defined in all but one study [27], and the sample recruited was suitable for the study population for all but one study [27]. However, in four studies the sampling strategy was unlikely to represent the target population [24-27].

Methods were sufficiently described in eight studies to enable them to be repeated [21, 24, 27, 29-33] and eight studies described their basic data adequately [21, 24, 2833]. Three studies described measures taken to address non-responders or missing data $[29,31,32]$. The results in all 11 studies were internally consistent. Only five studies mentioned funding sources or conflicts of interest $[21,27-29,31]$ and three studies did not report on ethical approvals or consent $[27,32,33]$.

\section{Discussion}

To our knowledge this is the first review to examine the prevalence of current (12-month) alcohol dependence and to describe how it is measured in Indigenous Peoples in similarly colonised countries. We identified 11 reports published between 1992 and 2020 among Indigenous Peoples in New Zealand, Canada, and the USA. No reports from Australia were identified. We highlight the need for more and unbiased data on prevalence of current alcohol dependence in Indigenous communities. Also screening, assessment and diagnostic tools and instruments need to be validated for Indigenous Peoples in a cross-cultural context. Indigenous Peoples need to be consulted to see how alcohol dependence criteria are translated locally. Interviewers using mainstream tools and instruments need to understand Indigenous Peoples' background and worldviews to understand alcohol dependence. Working in partnership with local Indigenous Peoples can inform this process. A clearer understanding of the prevalence of current alcohol dependence can help inform an estimate of the type and scope of alcohol intervention and treatment services needed for each community.

\section{Prevalence of current alcohol dependence}

In all nine prevalence studies the total prevalence was similar or higher than in the general population (e.g. in the NZ study, $3.9 \%$ versus $1.3 \%$ [13]; USA only studies, $6.0-33.3 \%$ versus $3.8 \%$ [15]). As in general populations, in all but one study [30] males had a higher prevalence of dependence than females, where gender-specific prevalence was provided (3.0-32.8\% versus $1.3-7.6 \%$ ) [21, 25, 28, 29, 33].

Prevalence studies which used a stratified sampling strategy $(n=5)[21,28,31-33]$ tended to report a lower prevalence of dependence than those that used convenience sampling $(n=2)[24,25](3.9-16.6 \%$ versus 18.8-33.3\%). However, studies using a combination of a convenience and roll-based strategy, contacting all eligible participants, reported a similarly low prevalence (3.8$4.2 \%)[29,30]$ to studies with stratified sampling. Future studies need to strive for recruitment strategies that can yield a representative prevalence of alcohol dependence within communities. Strategies should include working with local Indigenous people, community leaders and service providers to better understand how to reach a broad range of individuals [37].

All but one [28] of the USA-only community samples, drawn from specific First Nations communities, [24, 25] had a higher prevalence of current alcohol dependence than US national surveys of First Nations peoples [21, 31, 33] (18.8-33.3\% versus 6.1-16.6\%). Because of selection bias applying to either individuals or whole communities the study findings may not be able to be generalised to other Indigenous communities.

\section{Detecting alcohol dependence}

All but one tool used in the included studies have been validated for general communities. This review identified two tools used to screen for dependence (SMAST, CAGE/CAGE-T) that have been validated in Indigenous communities against criteria for lifetime dependence $[26,27]$. These were found to have good accuracy. Nonetheless the authors questioned the validity of SMAST because of the need for high cut-offs, which vary by community and gender [26]. The authors concluded that the modified CAGE-T did not add any diagnostic value compared to the standard CAGE [27]. Future studies are needed to validate tools against the criteria of current 
alcohol dependence. This would better help inform current local prevention and treatment needs.

Some tools have been translated and validated in other languages (e.g. AUDIT, CIDI), but as complex as translation is, translating Indigenous values and worldviews (e.g. the passing on of oral lore, culture, family values, and traditional knowledge) can be a more demanding process [7]. As these values are not embedded in these tools, consultation is needed with Indigenous communities to determine how criteria of dependence could be best translated into local contexts [38]. Mainstream tools or dependence criteria may or may not be accurate when screening, assessing or diagnosing alcohol dependence in an Indigenous population. In some communities the differing context can make items used to assess dependence difficult to interpret, unless these are 'translated' through a cultural lens $[39,40]$. For example, an Indigenous person's responsibilities to community and to Country may be at least as important as responsibilities 'in the home.' Furthermore, limited employment and educational opportunities in some communities may make questions about interference with work and study less relevant.

Some screening tools (e.g. AUDIT, CAGE) raise questions about feelings of guilt or shame in relation to drinking alcohol, for example, "How often during the last year have you had a feeling of guilt or remorse after drinking?" (AUDIT, Q7) [16]. If an individual indicates yes, the feeling of guilt may not necessarily relate to quantity or things said and done whilst drinking. Rather, the guilt could be from internalised racism, or internalised stigma of Indigenous people in relation to alcohol. On the other hand, an individual drinking heavily may experience no guilt or remorse if drinking large quantities is the social norm within that community. Interviewers utilising tools should consider an individual's background and worldviews and as every Indigenous community is different, interviewers benefit from training by local Indigenous people [41].

None of the eight tools used to screen, assess or diagnose alcohol dependence were developed specifically for Indigenous Peoples. In an Australian context, the Indigenous Risk Impact Screen (IRIS) is an Indigenous-specific screening tool which has been validated in an Australian Indigenous population (Queensland). However, IRIS provides a combined measure of risk from alcohol and substance use. For this reason, studies using IRIS were not included in this systematic review.

\section{Implications for policy, practice and research}

There is a need for more studies on prevalence of current alcohol dependence to inform prevention and treatment efforts in Indigenous communities internationally [42]. Assessing current prevalence is more useful than lifetime dependence for estimating current treatment needs. Large numbers of individuals who have experienced alcohol dependence may enter stable remission and not need treatment $[29,43]$. In one national study on American Indians and Alaskan Natives, the prevalence of lifetime alcohol dependence was more than three times that of current dependence (19.7\% versus $6.1 \%$, respectively) [21]. Prevalence findings inform the need for health promotion and treatment strategies. The findings can inform the balance of funding allocation between primary health care and specialist treatment services. Health promotion and treatment needs may also vary by gender or age [44]. Accordingly, to assess need, studies should stratify results by gender and age.

Researchers and clinicians should work in partnership with local Indigenous community members to take into consideration local worldviews and culture [38, 41]. They also should ensure research approaches (e.g. sampling methods and approach to recruit individuals) are co-designed with Indigenous Peoples and the local community. This may require extensive consultation with Indigenous leaders and community members over a long period time to understand the community and people. Structured interviews in the hands of a culturally-aware interviewer could also assist screening, assessment and diagnostic tools to be understood in a cross-cultural context $[39,40,45]$.

\section{Limitations}

This systematic review excluded studies that examined only lifetime prevalence of alcohol dependence. A systematic review of that research would also be useful to indicate the prevalence of those who (if in remission) could relapse in the future. Another systematic review could focus on individuals with milder AUDs (harmful use or abuse). Studies of specialised sub-populations were excluded from the current study (e.g. hospital inpatients and prison inmates). The prevalence of alcohol dependence in these groups was expected to be higher than in representative community samples. It is possible that some eligible studies were overlooked, despite careful screening, because titles and abstracts did not give a clue to relevant data contained within. It is also possible that we may have missed studies that report on dependence in general populations, but have a sub-analysis reporting on Indigenous populations. Grey literature was excluded as were non-English language publications.

\section{Conclusion}

Prevalence of current alcohol dependence varied considerably depending on study methods. Future studies should strive to recruit representative samples from Indigenous communities to give a more accurate 
estimate of the prevalence of current alcohol dependence. This review also highlighted the need for more alcohol dependence screening, assessment and diagnostic tools to be developed and validated by and for Indigenous populations. These tools should take into account local values and worldviews, and concepts underpinning the criteria in these tools should be clear. Leadership from local Indigenous community members, clinicians and researchers is a crucial part of future research in this area. Understanding the prevalence of current dependence can help inform communities. It can also help inform allocation of government funding for treatment needs.

\begin{abstract}
Abbreviations
AU: Australia; AUD: Alcohol use disorder; AUDADIS: Alcohol Use Disorder and Associated Disabilities Interview Schedule; AUDIT: Alcohol Use Disorders Identification Test; AXIS: Appraisal Tool for Cross-Sectional Studies; CIDI:WHO-Composite International Diagnostic Interview; DIS: Diagnostic Interview Schedule; DSM: Diagnostic and Statistical Manual of Mental Disorders; ICD: International Classification of Diseases; IRIS: Indigenous Risk Impact Screen; MAST: Michigan Alcoholism Screening Test; NZ: New Zealand; PRISMA: Preferred Reporting Items for Systematic Reviews and Meta-Analyses; ROC: Receiver operating characteristic; SADS: The Schedule for Affective Disorders and Schizophrenia; UM-CIDI: University of Michigan-Composite International Diagnostic Interview; USA: United States of America; WHO: World Health Organization; WMHCIDI: World Mental Health-Composite International Diagnostic Interview.
\end{abstract}

\section{Acknowledgements}

Bernadette Carr (Academic Liaison Librarian) from the University of Sydney.

\section{Authors' contributions}

TW: led the registration of the study with PROSPERO; designed the search terms with a university librarian; conducted a systematic literature search; conducted title and abstract screen, full-text screen and data extraction; conducted literature review; led the writing of the manuscript, tables and figure. KC: contributed to title and abstract screen and data extraction; provided input into PROSPERO registration; adjudicated screening and data extraction process when required; independently checked data extraction; reviewed drafts of manuscript, tables and figure; oversaw scientific integrity of the study. JC: provided input into PROSPERO registration; conducted a systematic literature search; title and abstract screen, full-text screen and data extraction; reviewed drafts of manuscript, tables and figure. KL: conceived the study; provided input into PROSPERO registration; conducted title and abstract screen, full-text screen and data extraction; reviewed drafts of manuscript, tables and figure. All authors read and approved the final manuscript.

\section{Funding}

This work was supported by the Australian National Health and Medical Research Council (NHMRC) through the Centre of Research Excellence in Indigenous Health and Alcohol (\#1117198), a Project Grant (\#1087192), and a Practitioner Fellowship for K Conigrave (\#1117582).

\section{Availability of data and materials}

Data for this project is stored at the University of Sydney based at Drug Health Service, KGV Building, Missenden Road, Camperdown New South Wales, 2050 Australia.

\section{Ethics approval and consent to participate}

Ethics approval was not sought as no original data were collected for this study. This study is a systematic review of existing published peer-reviewed journal articles.

\section{Consent for publication}

Not applicable.

\section{Competing interests}

The authors declare that they have no competing interests.

\section{Author details}

${ }^{1}$ Faculty of Medicine and Health, Discipline of Addiction Medicine, NHMRC Centre of Research Excellence in Indigenous Health and Alcohol, The University of Sydney, King George V Building, 83-117 Missenden Road, Camperdown, NSW 2050, Australia. ${ }^{2}$ Royal Prince Alfred Hospital, Drug Health Services, Camperdown, NSW, Australia. ${ }^{3}$ Centre for Alcohol Policy Research, La Trobe University, Bundoora, VIC, Australia.

Received: 4 February 2020 Accepted: 9 September 2020

Published online: 17 September 2020

\section{References}

1. Kirmayer $L$, Brass GM, Tait CL. The mental health of Aboriginal peoples: transformations of identity and community. Can J Psychiatry. 2000:45(7):607-16.

2. Dale E, Kelly PJ, Lee KK, Conigrave JH, Ivers R, Clapham K. Systematic review of addiction recovery mutual support groups and Indigenous people of Australia, New Zealand, Canada, the United States of America and Hawaii. Addict Behav. 2019;98:106038.

3. Ritter A, Berends L, Chalmers J, Hull P, Lancaster K, Gomez M. New horizons: the review of alcohol and other drug treatment services in Australia. Sydney: Drug Policy Modelling Program, National Drug and Alcohol Research Centre; 2014.

4. Brett J, Lee KSK, Gray D, Wilson S, Freeburn B, Harrison K, et al. Mind the gap: what is the difference between alcohol treatment need and access for Aboriginal and Torres Strait Islander Australians? Drug Alcohol Rev. 2016;35(4):456-60.

5. World Health Organization. ICD-11 Geneva: World Health Organization; 2018. https://icd.who.int/browse11/l-m/en\#/. http://id.who.int/icd/entit y/1580466198

6. American Psychiatric Association. DSM-V Washington: American Psychiatric Association; 2013. https://www.psychiatry.org/psychiatrists/pract ice/dsm.

7. Room R, Janca A, Bennett LA, Schmidt L, Sartorius N. WHO cross-cultural applicability research on diagnosis and assessment of substance use disorders: an overview of methods and selected results. Addiction. 1996;91(2):199-220

8. Saunders JB, Conigrave KM, Latt NC, Nutt DJ, Marshall EJ, Ling W, et al. Addiction medicine. Oxford: Oxford University Press; 2016.

9. Haber P, Lintzeris N, Proude E, Lopatko O. Quick reference guide to the treatment of alcohol problems: companion document to the guidelines for the treatment of alcohol problems. Canberra: Australian Government Commonwealth Department of Health and Ageing; 2009. p. 9.

10. Chikritzhs T, Liang W. Does the 2008 NATSISS underestimate the prevalence of high risk Indigenous drinking. Surv Anal Indigen Policy Aust Soc Sci Perspect. 2012;32:49-64.

11. Chikritzhs T, Brady M. Fact or fiction? A critique of the National Aboriginal and Torres Strait Islander Social Survey 2002. Drug Alcohol Rev. 2006;25(3):277-87.

12. Teesson M, Hall W, Slade T, Mills K, Grove R, Mewton L, et al. Prevalence and correlates of DSM-IV alcohol abuse and dependence in Australia: findings of the 2007 National Survey of Mental Health and Wellbeing. Addiction. 2010;105(12):2085-94.

13. Wells JE, Oakley Browne MA, Scott KM, McGee MA, Baxter J, Kokaua J. Prevalence, interference with life and severity of 12 month DSM-IV disorders in Te Rau Hinengaro: The New Zealand Mental Health Survey. Aust N Z J Psychiatry. 2006;40(10):845-54

14. World Health Organization. Global status report on alcohol and health 2018. Geneva: World Health Organization; 2018.

15. Hasin DS, Stinson FS, Ogburn E, Grant BF. Prevalence, correlates, disability, and comorbidity of DSM-IV alcohol abuse and dependence in the United States. Arch Gen Psychiatry. 2007;64(7):830-42.

16. Babor TF, Higgins-Biddle JC, Saunders JB, Monteiro MG. The alcohol use disorders identification test. Geneva: World Health Organization; 1992.

17. Mayfield D, McLeod G, Hall P. The CAGE questionnaire: validation of a new alcoholism screening instrument. Am J Psychiatry. 1974;131(10):1121-3. 
18. Selzer ML. The Michigan Alcoholism Screening Test: the quest for a new diagnostic instrument. Am J Psychiatry. 1971;127(12):1653-8.

19. Wittchen $\mathrm{H}-\mathrm{U}$. Reliability and validity studies of the WHO-Composite International Diagnostic Interview (CIDI): a critical review. J Psychiatr Res. 1994;28(1):57-84.

20. Endicott J, Spitzer RL. A diagnostic interview: the schedule for affective disorders and schizophrenia. Arch Gen Psychiatry. 1978;35(7):837-44.

21. Brave Heart MYH, Lewis-Fernández R, Beals J, Hasin DS, Sugaya L, Wang $\mathrm{S}$, et al. Psychiatric disorders and mental health treatment in American Indians and Alaska Natives: results of the National Epidemiologic Survey on Alcohol and Related Conditions. Soc Psychiatry Psychiatr Epidemiol. 2016;51(7):1033-46.

22. Prospero. University of York; [Available from: https://www.crd.york.ac.uk] PROSPERO/.

23. Downes MJ, Brennan ML, Williams HC, Dean RS. Development of a critical appraisal tool to assess the quality of cross-sectional studies (AXIS). BMJ Open. 2016;6(12):e011458.

24. Gill K, Elk ME, Deitrich RA. A description of alcohol/drug use and family history of alcoholism among urban American Indians. American Indian and Alaska Native Mental Health Research. J Natl Center. 1997:8(1):41-52.

25. Kinzie JD, Leung PK, Boehnlein J, Matsunaga D, Johnson R, Manson S, et al. Psychiatric epidemiology of an Indian village. J Nerv Ment Dis. 1992;180(1):33-9.

26. Robin RW, Saremi A, Albaugh B, Hanson RL, Williams D, Goldman D. Validity of the SMAST in two American Indian tribal populations. Subst Use Misuse. 2004;39(4):601-24.

27. Saremi A, Hanson RL, Williams DE, Roumain J, Robin RW, Long JC, et al. Validity of the CAGE questionnaire in an American Indian population. J Stud Alcohol. 2001;62(3):294-300.

28. Spicer P, Beals J, Croy CD, Mitchell CM, Novins DK, Moore L, et al. prevalence of DSM-III-R alcohol dependence in two American Indian populations. Alcohol Clin Exp Res. 2003;27(11):1785-97.

29. Walls M, Sittner KJ, Whitbeck LB, Herman K, Gonzalez M, Elm JH, et al. Prevalence of mental disorders from adolescence through early adulthood in American Indian and First Nations communities. Int J Ment Health Addict. 2020

30. Whitbeck LB, Hoyt D, Johnson K, Chen X. Mental disorders among parents/caretakers of American Indian early adolescents in the Northern Midwest. Soc Psychiatry Psychiatr Epidemiol. 2006;41(8):632-40.

31. Grant BF, Chou SP, Saha TD, Pickering RP, Kerridge BT, Ruan WJ, et al. Prevalence of 12-month alcohol use, high-risk drinking, and DSM-IV alcohol use disorder in the United States, 2001-2002 to 2012-2013. JAMA Psychiatry. 2017;74(9):911-23.

32. Baxter J, Kani Kingi T, Tapsell R, Durie M, Mcgee MA, Team NZMHSR. Prevalence of mental disorders among Māori in Te Rau Hinengaro: The New Zealand Mental Health Survey. Aust N Z J Psychiatry. 2006;40(10):914-23.

33. Grant BF, Dawson DA, Stinson FS, Chou SP, Dufour MC, Pickering RP. The 12-month prevalence and trends in DSM-IV alcohol abuse and dependence: United States, 1991-1992 and 2001-2002. Drug Alcohol Depend. 2004;74(3):223-34

34. Grant BF, Harford TC, Dawson DA, Chou PS, Pickering RP. The Alcohol Use Disorder and Associated Disabilities Interview schedule (AUDADIS): reliability of alcohol and drug modules in a general population sample. Drug Alcohol Depend. 1995;39(1):37-44.

35. Robins L, Helzer J, Goldring E, Cottler L. National Institute of Mental Health (NIHM) Diagnostic Interview Schedule: version III revised: NIHM; 1989

36. Kessler RC, Abelson J, Demler O, Escobar Jl, Gibbon M, Guyer ME, et al. Clinical calibration of DSM-IV diagnoses in the World Mental Health (WMH) version of the World Health Organization (WHO) Composite International Diagnostic Interview (WMH-CIDI). Int J Methods Psychiatr Res. 2004;13(2):122-39.

37. Lee KSK, Fitts MS, Conigrave JH, Zheng C, Perry J, Wilson S, et al. Recruiting a representative sample of urban South Australian Aboriginal adults for a survey on alcohol consumption. BMC Med Res Methodol. 2020;20(1):1.

38. Dickerson D, Baldwin JA, Belcourt A, Belone L, Gittelsohn J, Keawe'Aimoku Kaholokula J, et al. Encompassing cultural contexts within scientific research methodologies in the development of health promotion interventions. Prev Sci. 2020;21(S1):33-42.

39. James D, Shakeshaft A, Munro A, Courtney R. The need to move from describing to evaluating the effectiveness of Indigenous drug and alcohol residential rehabilitation services: a systematic review. Current Drug Abuse Reviews. 2018;10:52-67.

40. Brown GL, Albaugh BJ, Robin RW, Goodson SG, Trunzo M, Wynne DK, et al. Alcoholism and substance abuse among selected southern Cheyenne Indians. Cult Med Psychiatry. 1992;16(4):531-42.

41. Whitesell NR, Mousseau A, Parker M, Rasmus S, Allen J. Promising practices for promoting health equity through rigorous intervention science with Indigenous communities. Prev Sci. 2020;21(Suppl 1):5-12.

42. Blue Bird Jernigan V, D'Amico EJ, Duran B, Buchwald D. Multilevel and community-level interventions with Native Americans: challenges and opportunities. Prev Sci. 2020;21(1):65-73.

43. Dawson DA, Goldstein RB, Grant BF. Rates and correlates of relapse among individuals in remission from DSM-IV alcohol dependence: a 3-year follow-up. Alcohol Clin Exp Res. 2007;31(12):2036-45.

44. Nutbeam D, Harris E, Wise W. Theory in a nutshell: a practical guide to health promotion theories. New York: McGraw-Hill; 2010.

45. Walter M, Suina M. Indigenous data, indigenous methodologies and indigenous data sovereignty. Int I Soc Res Methodol. 2014;51(08):51-4519-51.

\section{Publisher's Note}

Springer Nature remains neutral with regard to jurisdictional claims in published maps and institutional affiliations.
Ready to submit your research? Choose BMC and benefit from:

- fast, convenient online submission

- thorough peer review by experienced researchers in your field

- rapid publication on acceptance

- support for research data, including large and complex data types

- gold Open Access which fosters wider collaboration and increased citations

- maximum visibility for your research: over $100 \mathrm{M}$ website views per year

At BMC, research is always in progress.

Learn more biomedcentral.com/submissions 